\title{
POST-DOCTORAL AND NON-FACULTY DOCTORATE RESEARCHERS IN ENGINEERING EDUCATION: DEMOGRAPHICS AND FUNDING
}

\author{
Kehdinga George \\ Fomunyam \\ Mangosuthu University of Technology, South Africa. \\ Email:Kehdinga.george@mut.ac.za Tel:0027610340745
}

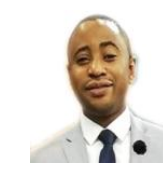

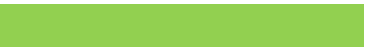

ABSTRACT

Article History

Received: 4 August 2020 Revised: 10 September 2020

Accepted: 30 September 2020

Published: 14 October 2020

\section{Keywords}

Demographics

Engineering education

Funding

Non-faculty doctorate

Post-doctoral appointee Researchers.

The driving force behind research in many countries is funding for research and development. The research at postgraduate level is predicated on a core research group championed by one principal investigator which might include staff scientists, postdoctoral appointees, non-faculty doctorate researchers, or graduate students and they play major roles in supporting the day to day duties in a research laboratory in order to gain more knowledge to continue their own independent research careers. In this case study, postgraduate postdoctoral appointees and doctorate holding non-tenure researchers in engineering were the study group and secondary data from National Center for Science and Engineering Statistics (2018) was used in this study. From this result, it was noticeable that there were more of postdoctoral appointees in units much more than the other categories. There were more males than females among postdoctoral appointees and non-faculty doctorate researchers in engineering education. Findings reveal that most prominent primary sources of support for postdoctoral appointees are federal and nonfederal domestic. From the primary mechanism of support, research grants were the most available for post-doctoral appointees. This study therefore recommends that there should be more inclusion for females in engineering education and efforts be intensified on increasing funding in postdoctoral engineering education.
\end{abstract}

Contribution/Originality: This study contributes to existing literature by examining the demographics and funding of post-doctoral appointees and non-faculty doctorate researchers in engineering education. Using recent data from the National Center for Science and Engineering Statistics, this study exposes the need for increased funding especially for females in several fields of engineering education.

\section{INTRODUCTION}

Engineering has been defined by the Royal Society of Engineers as the creative application of scientific principles to invent, design, build, maintain and improve structures, machines, devices, systems, materials and processes. This definition of engineering is broad as it highlights the multi-faceted application and benefits of engineering. Engineers are creative and they deploy their creativity to proffer solution to the problems of the world and help build future. Engineering education is such a broad discipline that it encompasses a range of specialized fields of engineering, each with a more specific emphasis on particular areas of applied science, and technology (Panchangam, 2015). Maillardet (2004) defines engineering as a three-legged structure, resting on science, mathematics and technology. There are various fields of engineering discipline which includes aerospace, chemical and process, civil and environmental, computing and communication, electrical and electronics, energy and power, 
materials and mining, manufacturing and design, medical and bioengineering, transport and mechanical and many others. Most innovations are seen on the global front occurring as a result of trained personnel in the field of engineering and technology (Adegbuyi \& Uhomoibhi, 2008)

Ahmed, Plotkin, Qiu, and Kawahara (2015) observe that the driving force behind research in many countries is funding for research and development. The standard model of academic scientific research that has evolved in the United States over the years is predicated on a core research group championed by one principal investigator which might include staff scientists, postdoctoral appointees, non-faculty doctorate researchers, or graduate students and they play major roles in supporting the day to day duties in a research laboratory in order to gain more knowledge to continue their own independent research careers (Stephan, 2014). Though there are issues on clearly delineating between doctoral appointees and non-faculty doctorate researchers, the latter was defined as individuals who are neither postdocs nor faculty members and are primarily involved in research (Einaudi, Heuer, Green, \& Kang, 2015). The post-doctoral setting is now an international one with people from various ethnicities and background. Though postdoctoral appointees are pivotal as they play substantial role in the United States, they are constrained by various concerns such as language and customs as a result of their ethnicity and race, difficulty in teaching and other professional abilities as a result of poor language abilities, lower compensation compared to postdoctoral appointees from the United States, visa issues, social security, housing and language skills. Evidence from various research conducted revealed that more males are involved in engineering education than females. This is in line with the findings of National Science Foundation (2006) which revealed that engineering education as a discipline has primarily been in the purview of white males. This implies that in terms of sex, males have primarily dominated engineering education.

Research training beyond $\mathrm{PhD}$ continues to be a defining moment for researchers and it is a temporary period of mentored advanced training to enhance the professional skills, competence, qualities and research independence that is needed for their career progression. This is influenced and dependent on the research discipline, source of funding, mechanism of support, visa status and type of degree. Consequently, this study examined the demographics and funding of postdoctoral appointees and non-faculty doctorate researchers in engineering education all United States academic institutions.

\section{METHODOLOGY OF RESEARCH}

\subsection{Data Collection}

Data was collected from graduate students and post doctorates in science and engineering using a questionnaire. The survey of graduate students and post doctorates in science and engineering (GSS) is an annual census of all academic institutions in the United States and its territories (Guam and Puerto Rico) granting research-based master's degree or doctorate in science and engineering or selected health field as of the fall term of the survey year. The survey data were collected through coordinators at some of these eligible academic institutions that granted research-based masters or doctoral degrees in science, engineering and selected health (SEH) fields. Coordinators were assigned by their institution and were responsible for identifying all GSS eligible units, collecting the requested data, and submitting the data to the survey contractor.

Coordinators were provided access to the GSS Web survey to report aggregate counts on enrolled masters and doctoral students, postdocs, and doctorate holding non-faculty researcher (NFRs) in each eligible unit, as of the fall term of academic year 2018. Reporting is done by the coordinator uploading a file with requested data to the GSS website, which automatically aggregates the data and populates the cells of the Web survey instrument for each eligible unit. Alternatively, coordinators manually entered data into the Web survey. Hard copies of the survey worksheets and GSS-eligible code lists were also mailed to the institution coordinators as reference. The Web survey is the primary mode of data submission. Based on the review of respondent data and explanatory comments 
provided by the respondents, follow-up telephone calls were made or e-mails were sent to clarify responses, when needed.

\section{DATA ANALYSIS}

\subsection{Data Processing}

All data submitted by institution coordinators are reviewed to ensure that data fields are complete, and that data are internally consistent. Data that are substantially different from previously reported data are flagged for review by the survey contractor. If additional information or corrections are needed, institution coordinators are contacted by telephone or e-mail and are asked to correct and resubmit the survey data.

\subsection{Estimation Techniques}

The survey is a census of eligible units; therefore, weighting for sampling is not applicable. Imputation rather than weighting is used to adjust for unit non-response; imputation is also used for item non-response.

\section{METHOD}

The survey target population is all academic institutions in the United States and its territories (Guam and Puerto Rico) that grant research-based masters or doctoral degrees in SEH fields. This population includes branch campuses, affiliated research centers and health facilities, and separately organized components, such as medical or dental schools, schools of nursing, and schools of public health.

\subsection{Sampling Frame}

Secondary data from the Yamaner (2018) revealed that the total universe included 19,592 units at 715 academic institutions in the United States that granted research-based master's degrees or doctorates in SEH fields. The survey data was collected through coordinators at eligible institutions. Coordinators were assigned by their institution and were responsible for identifying all GSS eligible units, collecting the requested data, and submitting the data to the survey contractor. Coordinators were provided access to the GSS Web survey to report aggregate counts on enrolled masters and doctoral students, postdocs, and NFRs in each eligible unit, as of the fall term of academic year 2018. Reporting was done by the coordinator uploading a file with requested data to the GSS website, which automatically aggregates the data and populates the cells of the Web survey instrument for each eligible unit. Alternatively, coordinators may manually enter data into the Web survey. Hard copies of the survey worksheets and GSS-eligible code lists are also mailed to the institution coordinators as reference. The Web survey was the primary mode of data collection.

\subsection{Sample Design.}

The sample design comprised eligible academic institutions identified through IPEDS (The integrated postsecondary education data system).

\section{LITERATURE REVIEW}

\subsection{Historical Context of Postdoctoral Education in the United States}

The reality of the postdoctoral experience began to align in the first half of the $20^{\text {th }}$ century when the pace of scientific research was still on a small scale. The massive shift in the line of "big science" during and after the World War II which gained traction after the subsequent decades has resulted to creating a structure and system that will need a large team of graduate students, postdoctoral researchers and other types of researchers being under the control and directive of a principal investigator. There was a need for highly educated, specialized, and productive professionals, who would contribute to the economic and social growth of each country (Kwiek \& Antonowicz, 
2015; Weijden, Teelken, De Boer, \& Drost, 2016). With the increase in demand for junior workers increasing, the number of research faculty positions which the junior researchers could move to has not kept pace predominantly within the academic institutions. While tenured faculty members were not retiring at a pace in which aspiring replacements were being trained which results in a system which has created expectations for career progression that might not be met (National Academic Press, 2014).

The prevailing system of postdoctoral research in the United States became popular after the First World War (World War I) which was championed by the National Research Council and the Rockefeller Foundation to encourage basic research in physics and chemistry so as to be in competition and keep pace with some other leading nations like Germany. Taking a retrospective look at history, in the year 1920-1930, postdoctoral researchers were charged with the role of directing the day to day affairs in the laboratory giving the principal investigator time to attend to other duties such as supervising research, teaching, sourcing and obtaining funds and managing other administrative duties (Assmus, 1993). This confers more impetus on the postdoctoral researchers as they had to contribute more to research and day to day activities in the laboratory.

With the aftermath of the World War II, there was increased funding for basic research at universities which shifted massively from foundations, private bodies to the federal government. This had an effect on the growth of postdoctoral researchers as a result of increase in funding. Consequently, in 1960, about 10\% of the doctoral graduates went forward with a postdoctoral position though the spread was uneven. There was more focus on biomedical fields which received more attention than other areas of engineering and science (National Research Council, 1969). Between 1985 and 2011, approximately 690,000 postdocs were enrolled in the United States (Ahmed et al., 2015). The federal grants only covered individual faculty members at universities and only covered expenses for research but later on, indirect rates received massive increase and salaries for postdoctoral researchers were added to the grants (Stephan, 2014).

\subsection{Training and Postdoctoral Education in the United States}

Research training after a doctoral degree in engineering can be a viable period for many researchers and also a right step to becoming more adept in research in their discipline. The experiences gained during this postdoctoral year helps in encouraging the development of research careers in line with their discipline. According to National Academic Press (2014) postdoc is a truncation of the adjective postdoctoral which literally typifies a period of time and is helpful in modifying various positions within the academic institution such as traineeships, fellowships, research scientists and other related titles. A post doc is a stage in the education, training and career development of an engineer that is characterized only by the period of time and not by position. The postdoctoral stage is meant to be a continuation and enhancement of the in-depth education of the doctoral student. As stated by Ahmed et al. (2015) postdoctoral fellows are scientists who have completed doctoral studies and have been appointed as temporary researchers. With the position only revealing a time period other than the position, it comes with lots of drawbacks for identifying people during this stage and this affects effort to collect data.

The ideal pathway for a postdoctoral researchers' path is typified by National Academic Press (2014). It states that a doctoral degree recipient who is self-motivated and is selected by using individual preference receives further scientific training to boost previous training gotten from the graduate school for a delineated period of time before moving forward in their careers to a full time research position. Under the guidance of a principal investigator, the postdoctoral researcher is exposed to new tools, techniques and methodologies of research and has access to wide professional network and relationships that might help in facilitating career progression for the individual. Under the guidance of the principal investigator, the postdoctoral appointee also engages in various researches and contributes to knowledge by publication which is the major currency in the academic and research world. It learns more about grants and grants winning and other important tools relevant to the discipline. Sometimes, at the end of 
the postdoctoral period, fellows are offered junior functions followed by employment in a lower-level, and subsequently a higher-level senior position such as a full professorship (Weijden et al., 2016).

National Academic Press (2014) also reveals that with the benefits of gaining relevant skills and knowledge from the principal investigator in the discipline, the individual who might be a postdoctoral appointee or doctorate holding non-faculty researcher contributes by providing highly skilled, low-cost research labor in the laboratory and consequently deploys new techniques that benefits the principal investigator's group. The individual therefore contributes to publications and grants and the entire productivity of the research group. The individual also has the opportunity to work with graduate students and other members in the laboratory (Weijden et al., 2016). With various functions in the laboratory, the postdoctoral appointee or doctorate holding non-faculty researchers can be involved in other functions such as teaching, fundraising, administration etc., if directed by the principal investigator.

\subsection{Funds and Grants for Postdoctoral Education in the United States}

It is important to note that the number of postdoctoral positions that were created as a result of research grants has increased steadily as revealed by National Academic Press (2014). It came to the knowledge of principal investigators that a lot of their postdoctoral researchers could not obtain independent research or faculty positions and there was a need to proffer solution to this. Weijden et al. (2016) in their study revealed that the major issue was the resolve of most postdocs to remain in academia, as only a few spent times in preparing for a career outside academia. What contributed to this is that many principal investigators that were trained after the World War II system do not have the requisite knowledge outside the academic institution. This implies that the principal investigators were oblivious to knowledge of other sectors that are critical to providing mentoring to the increasing number of students and postdoctoral researchers who would in the future further their career path in other positions other than independent, academic research. The little experience of principal investigators in other sectors has been a major bane to the massive career progression of students and postdoctoral researchers and the impetus is on how to increase synergy between the four walls of an academic institution and the outside world so that there will be cross fertilization of ideas from a scholarly perspective and from the industrial perspective. This has with it lots of benefits for the academic institutions, the principal investigators, the students and postdoctoral researchers, the industries, the society at large and the individuals in the society.

The current reality now is that most postdoctoral positions are domiciled in the universities and other research centers. Though the university does not have the capacity to provide jobs for all postdoctoral researchers at the expiration of their terms, the committee members were of the opinion that in most of the universities, the ideal situation is that the postdoctoral researchers will find jobs elsewhere (Weijden et al., 2016). In the same vein, private bodies and national laboratories sees the postdoctoral period as a chance to critically observe potential employees and some finally hire their own postdoctoral researchers at the termination of their research contracts. Major discussions about postdoctoral training considers basically researchers working within the universities while about 11 percent work at Federally Funded Research and Development Centers (FFRDCS) which includes national laboratories, industry research and development centers. With the divide between the employment patterns of postdoctoral appointees in the university and those outside the university such as those in the federal funded research and development centers, their experience differs. For instance, those outside the university earn higher salaries; have short term of appointment, well defined position, the probability of being hired for a permanent position is also high. To attract top talent in research, the FFRDCS postdoctoral fellows are increasing in importance (National Academic Press, 2014).

Funding for postdoctoral research positions within the universities are in three categories which are fellowships, training grants and research grants. It was observed that majority fall into research grants. A grant is often regarded as the most important career-boosting factor for a postdoc (Science Europe Working Group on 
Research Careers Co-Ordination, 2016). The research grants have been a veritable source to fund postdoctoral research and this was supported by nongovernmental sources such as those from foundations. Postdoctoral researchers with independent competitive fellowships can maintain some level of control over the choice of their research topics and can decide where to conduct their study and relocate to which confers some advantages on them. Whereas, training grants are awarded to research institutions and the choice of selection of postdoctoral researchers is done by the grant receiving institution, when the postdoctoral researcher acquires traineeship, she or he may maintain some degree of flexibility in the choice and selection of research topics. The most predominant source of funding mechanism is through the principal investigator who facilitates the recruitment of postdoctoral researchers who then work on research grant awards they have been able to acquire from federal or private sources. In situations like this, the postdoctoral researcher is under the tutelage and supervision of principal investigators in a chosen area of interest in their host laboratories with little mobility (National Academic Press, 2014; Science Europe Working Group on Research Careers Co-Ordination, 2016).

\section{FINDINGS AND DISCUSSION}

Results from Table 1 contain the demographic characteristics of postdoctoral appointees and non-faculty doctorate researchers. In the year 2018, result indicate that there were 7914 post-doctoral appointees in engineering disciplines and 3570 non-faculty doctorate researchers. Results indicates that there were 204 (28.5\%) of post-doctoral appointees in engineering education institutions, while there were 218 (26.7\%) of postdoctoral appointees in schools and $1011(5.2 \%)$ in units. From this result, it is noticeable that there were more of postdoctoral appointees in units much more than the other categories. Non-faculty doctorate researchers were also considered in this study and it was revealed that there were $164(22.9 \%)$ of non-faculty doctorate researchers in institutions, while there were $169(20.7 \%)$ of non-faculty doctorate researchers in schools and 751 (3.8\%) nonfaculty doctorate researchers in units. There were more non-faculty doctorate researchers in units than institutions and schools.

Table-1. Demographics of postdoctoral appointees and non-faculty doctorate researchers.

\begin{tabular}{|c|c|c|c|c|}
\hline & $\begin{array}{c}\text { Postdoctoral } \\
\text { appointees }\end{array}$ & & $\begin{array}{c}\text { Non-faculty doctorate } \\
\text { researchers }\end{array}$ & \\
\hline & Number & Percent & Number & Percent \\
\hline Institutions & 204 & 28.5 & 164 & 22.9 \\
\hline Schools & 218 & 26.7 & 169 & 20.7 \\
\hline Units & 1,011 & 5.2 & 751 & 3.8 \\
\hline All individuals & 7,914 & 100.0 & 3,570 & 100.0 \\
\hline Male & 6,046 & 76.4 & 2,749 & 77.0 \\
\hline Female & 1,868 & 23.6 & 821 & 23.0 \\
\hline U.S. citizens and permanent residents & 2,656 & 33.6 & NA & NA \\
\hline Hispanic or Latino & 127 & 1.6 & NA & NA \\
\hline Not Hispanic or Latino & NA & $\mathrm{NA}$ & NA & NA \\
\hline American Indian or Alaska Native & 4 & 0.1 & NA & NA \\
\hline Asian & 690 & 8.7 & NA & NA \\
\hline Black or African American & 77 & 1.0 & NA & NA \\
\hline $\begin{array}{l}\text { Native Hawaiian or Another Pacific } \\
\text { Islander }\end{array}$ & 1 & * & NA & NA \\
\hline White & 1,415 & 17.9 & NA & NA \\
\hline More than one race & 35 & 0.4 & $\mathrm{NA}$ & $\mathrm{NA}$ \\
\hline Unknown ethnicity and race & 307 & 3.9 & NA & $\mathrm{NA}$ \\
\hline Temporary visa holders & 5,258 & 66.4 & NA & NA \\
\hline
\end{tabular}

Sex as a demographic characteristic was also considered and it was revealed in Table 1 that there were $6046(76.4 \%)$ male's doctoral appointees and 2749 (77.0\%) male non-faculty doctorate researchers. This typifies that there were more males than females among postdoctoral appointees and non-faculty doctorate researchers in 
engineering education. This might be attributed to poor female enrollment in engineering education. Sex is a major factor to consider in engineering education and it's until recently that there was the clamor for more female inclusion in engineering education. This is in line with the findings of National Science Foundation (2006) which revealed that engineering education as a discipline has primarily been in the purview of white males. This implies that in terms of sex, males have primarily dominated engineering education. In times past, engineering education was highly stereotyped as a masculine discipline because of the nature of work that surrounds it. There are now concerns from policy makers on gender and careers to make the discipline more gender neutral so as to have more females in it. This in the long run will ensure equality and contribute to sustainability. The view of Blickenstaff (2005) also agrees with the result which maintained that women with advanced degree are widely underrepresented in STEM fields which engineering education is a part of. This shortfall in the number of women in engineering education has disadvantages as revealed by National Academy of Science (2007) which maintained that with limited number of women in academic STEM, it impedes scientific creativity and leads to a shortage of professionals (Kuenzi, 2008).

Out of all the postdoctoral appointees, it was revealed that 2656 (33.6\%) were United States citizens and permanent residents while United States citizens and permanent residents was not applicable for non-faculty doctorate researchers. Other ethnicity and race amongst postdoctoral appointees were Hispanic or Latino 127 (1.6\%), American India or Alaska native 4 (0.1\%), Asian 690 (8.7\%), black or African American 77 (1.0\%), Native Hawaiian or other pacific highlander $1\left(^{*}\right)$, white $1415(17.9 \%)$, more than one race $35(0.4 \%)$, unknown ethnicity and race 307 (3.9\%). From the other ethnicities and race considered for post-doctoral appointees, there were more Asians, white, Hispanic and Latinos. This is in line with the findings of UNESCO Institute for Statistics (2014) which revealed that Central Asia has the highest number of international students schooling abroad. This implies that there were more international postdoctoral appointees in other ethnicities and race than United States citizens and permanent residents. This is in line with the findings of Barton (2003) who observed that a large proportion of the US population will be composed of minorities.

The results in Table 1 also contain the visa status of post-doctoral appointees and non-faculty doctorate researchers and It was revealed that there were 5258 (66.4\%) temporary visa holders for postdoctoral appointees. This shows that there were more international postdoctoral appointees and non-faculty doctorate researchers. This agrees with the findings of Chow (2015) who maintained that the United States remains the top destination for international students.

Results in Table 2 contain funding for post-doctoral appointees and non-faculty doctorate researchers. The primary source of support for postdoctoral appointees is federal, nonfederal domestic, personal resources and unknown or not stated. Results indicate that the most prominent primary sources of support for postdoctoral appointees are federal $3709(46.9 \%)$ and nonfederal domestic 3609 (45.6\%). This implies that a large percentage of postdoctoral appointees depend on federal and nonfederal domestic sources for funding. It is important to bear in mind that pastoral appointees require huge financial commitment which their personal resources might not be able to guarantee, hence the need for other viable sources such as the federal and nonfederal domestic resources. A few of the postdoctoral appointees depended on their personal resource $98(1.2 \%)$ and unknown or not stated sources 498 (6.3\%). Funding is important for any postdoctoral appointee and for the various researches that will be carried out during that period; it comes with huge financial demands which the individual might not be able to bear unless there are some external supports from various sources. It is important to note that research is expensive and researches in engineering education are basically practical based which requires preferring real answers to solve daily human and societal problems. Getting the inputs, manpower and other things that will be needful for such research requires huge financial investment from various sources.

Apart from primary source of support for postdoctoral appointees, the primary mechanism of support is also important. The primary mechanisms of support available to postdoctoral appointees include research grants, 
fellowships, traineeship and other types of support. From the primary mechanism of support, research grants 5698 $(72.0 \%)$ was the most available for post-doctoral appointees. Postdoctoral appointees in furtherance to their academics are involved in more research that will confer more knowledge on their selected field of study hence, the need to have this primary mechanism of support. Research grants are given to help in the conduct of their various researches. There are also fellowships 755 (9.5\%) for postdoctoral appointees, traineeship 106 (1.3\%) and other types of support 1355 (17.1\%). Apart from the funding sources for postdoctoral appointees and non-faculty doctorate researchers, there is a need for proper mechanism of support for them which is rendered through fellowships, research grants, traineeships and other types of support.

Table-2. Funding for post-doctoral appointees and non-faculty doctorate researchers.

\begin{tabular}{l|c|c|c|c}
\hline \multicolumn{4}{c}{ Table-2. Funding for post-doctoral appointees and non-faculty doctorate researchers. } \\
\hline Funding & $\begin{array}{c}\text { Postdoctoral } \\
\text { appointees }\end{array}$ & $\begin{array}{c}\text { Non-faculty doctorate } \\
\text { researchers }\end{array}$ & Number & Percent \\
\hline Primary source of support & Number & Percent & $\mathrm{Na}$ & $\mathrm{Na}$ \\
\hline Federal & 3,709 & 46.9 & $\mathrm{Na}$ & $\mathrm{Na}$ \\
\hline Nonfederal domestic & 3,609 & 45.6 & $\mathrm{Na}$ & $\mathrm{Na}$ \\
\hline Personal resources & 98 & 1.2 & $\mathrm{Na}$ & $\mathrm{Na}$ \\
\hline Unknown or not stated & 498 & 6.3 & & $\mathrm{Na}$ \\
\hline Primary mechanism of support & & & $\mathrm{Na}$ & $\mathrm{Na}$ \\
\hline Fellowships & 755 & 9.5 & $\mathrm{Na}$ & $\mathrm{Na}$ \\
\hline Research grants & 5,698 & 72.0 & $\mathrm{Na}$ & $\mathrm{Na}$ \\
\hline Traineeships & 106 & 1.3 & $\mathrm{Na}$ & \\
\hline Other types of support & 1,355 & 17.1 & & \\
\hline
\end{tabular}

Results from Table 3 contain the degree types of postdoctoral appointees and non-faculty doctorate researchers. There are various options for them and from the table, it was revealed that majority of the postdoctoral appointees had doctoral degree 6265 (79.2\%) while 3008 (84.3\%) of non-faculty doctorate researchers had doctoral degree. The doctoral degree is basically academic and it offers the opportunity to develop the knowledge relevant for thriving within the academia. From the result, 87 (1.1\%) of the post-doctoral appointees had professional degree while $88(2.5 \%)$ of the non-faculty doctorate researchers had professional degree. Some of the post-doctoral appointees had dual degree $44(0.6 \%)$ while 28 (0.8\%) of non-faculty doctorate researchers had dual degree. The choice of the type of degree depends on the career path a person wants to embark on. For people looking for positions within the academia, a doctoral degree is appropriate for them.

Table-3. Degree type for postdoctoral appointees and non-faculty doctorate researchers.

\begin{tabular}{|c|c|c|c|c|}
\hline Degree type $^{b}$ & $\begin{array}{c}\text { Postdoctoral } \\
\text { appointees }\end{array}$ & & $\begin{array}{c}\text { Non-faculty doctorate } \\
\text { researchers }\end{array}$ & \\
\hline & Number & Percent & Number & Percent \\
\hline Doctoral degree & 6,265 & 79.2 & 3,008 & 84.3 \\
\hline Professional degree & 87 & 1.1 & 88 & 2.5 \\
\hline Dual degree & 44 & 0.6 & 28 & 0.8 \\
\hline Unknown & 1,518 & 19.2 & 446 & 12.5 \\
\hline
\end{tabular}

Table-4. Degree origin of postdoctoral appointees and doctorate holding nonfaculty researchers

\begin{tabular}{c|c|c|c|c}
\hline Degree origin & $\begin{array}{c}\text { Postdoctoral } \\
\text { Appointees }\end{array}$ & $\begin{array}{c}\text { Non-Faculty Doctorate } \\
\text { Researchers }\end{array}$ & Number & Percent \\
\hline United States & Number & Percent & NA & NA \\
\hline Foreign country & 3,005 & 38.0 & NA & NA \\
\hline Unknown & 2,151 & 27.2 & NA & NA \\
\hline
\end{tabular}

Note: * = value $<0.05 \%$; na = not applicable; citizenship, race and ethnicity, source of support, mechanism of support, and degree origin data are not collected for doctorate-holding nonfaculty researchers.

a Ethnicity and race data are available only for U.S. citizens and permanent residents.

b Doctoral degree includes PhD, ScD, DEng, etc.; professional degree includes MD, DVM, DO, DDS, etc.; dual degree includes both professional and doctoral degrees (MD-PhD, DVM-PhD, etc.).

"Field" refers to the field of the unit that reports postdoctorates and doctorate-holding nonfaculty researchers to the Survey of Graduate Students and Postdoctorates in Science and Engineering. Percentages may not add to total because of rounding. 
Results in Table 4 contain the degree origin of postdoctoral appointees and non-faculty doctorate researchers. Most 3005 (38.0\%) of the postdoctoral appointees had their degree from the United States while 2151 (27.2\%) of the post-doctoral appointees had their degree from foreign countries. This shows that a large percentage of the postdoctoral appointees had their degrees from the United States.

\section{SUMMARY, CONCLUSION AND RECOMMENDATION}

This study has examined demographics and funding of post-doctoral and non-faculty doctorate researchers in engineering education. It was revealed in the study that the standard model of academic scientific research that has evolved in the United States over the years is predicated on a core research group championed by one principal investigator which might include staff scientists, postdoctoral appointees, non-faculty doctorate researchers , graduate students etc. and they play major roles in supporting the day to day duties in a research laboratory while they gain more knowledge to continue their own independent research careers. Though there are issues on clearly delineating between doctoral appointees and non-faculty doctorate researchers, the latter was defined as individuals who are neither postdocs nor faculty members and are primarily involved in research. This study therefore recommends that there should be more inclusion for females in engineering education and efforts should be intensified on increasing funding in postdoctoral engineering education.

Funding: This study received no specific financial support.

Competing Interests: The author declares that there are no conflicts of interests regarding the publication of this paper.

\section{REFERENCES}

Adegbuyi, P., \& Uhomoibhi, J. (2008). Trends in the development of technology and engineering education in emerging economies. Multicultural Education \& Technology Journal, $2(3), \quad 132 \quad-139 . \quad$ Available at: https://doi.org/10.1108/17504970810900432.

Ahmed, M. Z., Plotkin, D., Qiu, B.-L., \& Kawahara, A. Y. (2015). Postdocs in science: A comparison between China and the United States. Bio Science, 65(11), 1088-1095. Available at: https://doi.org/10.1093/biosci/biv 125

Assmus, A. (1993). The creation of postdoctoral fellowships and the siting of American scientific research. Minerva, 31(2), 151183. Available at: https://doi.org/10.1007/bfo 1125433 .

Barton, P. E. (2003). Hispanics in science and engineering: A matter of assistance and persistence, educational testing service, policy information Report (pp. 40).

Blickenstaff, J. C. (2005). Women and science careers: Leaky pipeline or gender filter? Gender and Education, 17(4), 369-386. Available at: https://doi.org/10.1080/09540250500145072.

Chow, P. (2015). What international students think about US higher education? International higher education. 65, 10-12. Available at: https://doi.org/10.6017/ihe.2011.65.8568.

Einaudi, P., Heuer, R., Green, P., \& Kang, K. (2015). Examining the Reporting of nonfaculty doctorate researchers in the survey of graduate students and postdoctorates in science and engineering. Working Paper NCSES 15-201. Arlington, VA: National Science Foundation, National Center for Science and Engineering Statistics. Retrieved from: http://www.nsf.gov/statistics/2015/ncses 15201/.

Kuenzi, J. J. (2008). Science, technology and engineering, and mathematics (stem) education: Background, federal policy, and legislative action. Congressional research service Reports paper 35. Washington: Congressional Research Service.

Kwiek, M., \& Antonowicz, D. (2015). The changing paths in academic careers in European universities: Minor steps and major milestones. In Academic work and careers in Europe: Trends, challenges, perspectives (pp. 41-68). Cham: Springer.

Maillardet, F. (2004). What outcome is engineering education trying to achieve. In Brown, S. (Ed.), Effective Learning and Teaching in Higher Education (pp. 9-23). London: Taylor \& Francis e-library. 
National Academic Press. (2014). Committee to review the state of postdoctoral experience in scientist and engineers: Committee on science, engineering and public policy: Policy and global affairs: National academy of science. Paper presented at the National Academy of Engineering: Institute of Medicine. The Postdoctoral Experience Revisited: Changing Aspect of the Postdoctoral Experience. Washington DC.

National Academy of Science. (2007). Beyond bias and barriers. Fulfilling the potential of women in academic science and engineering. Edited by national academy of science committee on maximizing the potential of women in academic science and engineering, national academy of engineering and institute of medicine. Washington: National Academy Press.

National Science Foundation. (2006). Women, minorities, and persons with disabilities in science and engineering december 2006 update. Arlington, VA: National Science Foundation.

Panchangam, S. C. (2015). An introduction to engineering. Engineering and science focus: AITK, monthly bulletin. 10.13140/RG.13142.13141.14254.14486.

Science Europe Working Group on Research Careers Co-Ordination. (2016). Postdoctoral funding schemes in Europe: Survey Report, D/2016/13.324/9. Retrieved from: http://www.office@scienceeurope.org.

Stephan, P. (2014). The endless frontier: Reaping what Bush sowed? NBER Working Paper 19687. Retrieved from: http://www.nber.org/papers/w19687.

UNESCO Institute for Statistics. (2014). Global flow of tertiary-level students. Retrieved from: http://www.uis.unesco.org/Education/Pages/international-student-flow-viz.aspx Wiley Encyclopedia of Management, edited by Professor Sir Cary L Cooper.Copyright (C) 2014 John Wiley \& Sons, Ltd.

Weijden, I. D., Teelken, C., De Boer, M., \& Drost, M. (2016). Career satisfaction of postdoctoral researchers in relation to their expectations for the future. Higher Education, 72(1), 25-40. Available at: https://doi.org/10.1007/s 10734-015-9936-0.

Yamaner, M. (2018). Human resources statistics program: National center for science and engineering statistics national science foundation, Alexandria, VA 223 14. Retrieved from: https://www.nsf.gov/statistics/srvygradpostdoc/\#sd. responsible or answerable for any loss, damage or liability etc. caused in relation to/arising out of the use of the content. 